\title{
Novel Approaches for Efficient Antifungal Drug Action
}

\author{
Heejeong Lee and Dong Gun Lee* \\ School of Life Sciences, BK 21 Plus KNU Creative BioResearch Group, College of Natural Sciences, Kyungpook National University, Daegu \\ 41566, Republic of Korea
}

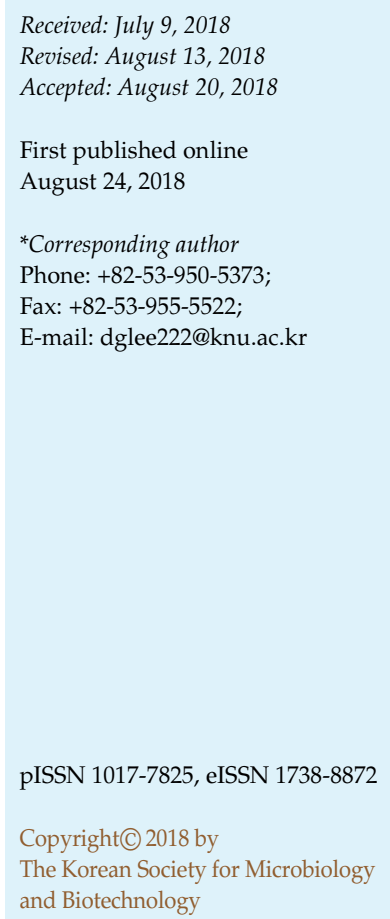

The emergence of multidrug-resistant microorganisms, as well as fungal infectious diseases that further threaten health, especially in immunodeficient populations, is a major global problem. The development of new antifungal agents in clinical trials is inferior to the incidence of drug resistance, and the available antifungal agents are restricted. Their mechanisms aim at certain characteristics of the fungus in order to avoid biological similarities with the host. Synthesis of the cell wall and ergosterol are mainly targeted in clinical use. The need for new approaches to antifungal therapeutic agents or development alternatives has increased. This review explores new perspectives on mechanisms to effectively combat fungal infections and effective antifungal activity. The clinical drug have a common feature that ultimately causes caspase-dependent cell death. The drugs-induced cell death pathway is associated with mitochondrial dysfunction, including mitochondrial membrane depolarization and cytochrome $c$ release. This mechanism of action also reveals antimicrobial peptides, the primary effector molecules of innate systems, to highlight new alternatives. Furthermore, drug combination therapy is suggested as another strategy to combat fungal infection. The proposal for a new approach to antifungal agents is not only important from a basic scientific point of view, but will also assist in the selection of molecules for combination therapy.

Keywords: Antifungal drugs, programmed cell death, antimicrobial peptide, drug combination, polyenes, azoles

\section{Introduction}

As modern medicine develops, patients are becoming more vulnerable to microbial infiltration as we gain the ability to manage diseases that have previously been refractory to medical and surgical intervention $[1,2]$. The widespread adoption of organ transplantation, tracheal intubation and endoscopic techniques, broad application of immunosuppressants, corticosteroids and antibiotics have increased the chances of fungal infections. Anticancer chemotherapy, new monoclonal antibodies with immunological properties, immunosuppressive drugs, and a broad spectrum of antimicrobials can disturb or violate the immune surveillance system [1,3]. Invasive fungal infections have increased significantly, coincident with the rising number of immunocompromised patients [3, 4]. In fact, more people die from these fungal infections all over the world at present than from tuberculosis or malaria [5]. Despite current treatments, fungal infections are a significant threat to severely ill individuals (e.g., due to immunosuppressive therapy after leukemia, organ transplantation or AIDS) [6, 7]. Most fungal infections were acquired by invasive candidiasis due to Candida spp. and invasive aspergillosis due to Aspergillus spp. [8-10].

Despite the incidence of a wide range of fungal pathogens, only a limited number of antifungal agents are prescribed [5]. However, currently available antifungal therapies vary considerably in terms of pharmacological properties, drugdrug interactions and potential for toxicity [11]. The limited armamentarium of currently available antifungal drugs is polyenes, azoles, and echinocandins and pyrimidine analogues [1, 11]. Allylamines are also present, but this class of compounds is only used for the treatment of superficial dermathophytic infections [1]. Unfortunately, 
continued overuse and misuse of these drugs in clinical applications cause serious problems. Due to inherent characteristics, microorganisms with low sensitivity to conventional drugs have appeared [7]. Although these drugs target a marked fungal pathway, there is an urgent need to develop new antifungal agents that are more effective, fungalspecific, have no or reduced toxicity, and simultaneously do not cause resistance [7]. Important considerations in the development of antifungal drug products include tissue site penetration, absorption, metabolic pathways, the effects of long-term dysfunction on medications and the need to monitor therapeutic drugs [11].

The antifungal drug pipeline is mostly dry [6]. Development of antifungal therapy has been a challenge due to the limited availability of novel targets, owing to the similarity of the metabolic pathways in pathogenic fungi and their higher eukaryotic hosts, such as humans [12]. Thus, identification of novel strategies for combating fungal infections and the development of broad-specificity antifungal drugs is urgently needed [12]. This review addresses approach strategies on the development of antifungal drugs.

\section{Mechanism of Action of Conventional Antifungal Drugs}

Unlike bacteria, which are prokaryotes, fungi are eukaryotes, so they have many similarities in host cells and metabolic pathways. The biological similarity between eukaryotic host and fungal pathogens has led to drug development focused on the functions and structures unique to fungi. Indeed, fungal cell walls, ergosterol, and cytosine deaminase are restricted [1, 13]. Effective antifungal agents are classified into three drug classes. Those drugs are the polyenes, azoles, and echinocandins (Table 1) [14-16].

\section{Polyenes}

Amphotericin B is the first antifungal agent developed and approved for the treatment of a broad spectrum of invasive fungal infections, including aspergillosis, candidiasis, blastomycosis, cryptococcosis, mucormycosis, histoplasmosis and sporotrichosis [11]. Amphotericin B formulations are recommended for the initial treatment of many unique fungal infections, especially those that are severe and life-threatening [11]. Typically, amphotericin B binds primarily to the ergosterol of the cytoplasmic membrane and inserts into the cytoplasmic membrane. After the formation of the pore-like structure, the integrity of the membrane is lost and the proton gradient gets destroyed, resulting in leakage of ions in the cell, causing osmotic instability $[13,14,17,18]$. The biological activity of amphotericin B depends mainly on the presence of sterols on the membrane lipids. The interaction of amphotericin B with ergosterol is more powerful than with cholesterol. This difference can be regarded as directly responsible for the specific selectivity of amphotericin B for the fungal membranes containing ergosterol. On the other hand, the drug's interaction with cholesterol, and its nonspecific binding to lipid membranes or other biomolecules are associated with apparent toxicity to patients [19]. However, pore formation is an insufficient mechanism to induce cell death [20]. The apoptotic pathway is reported as a process that takes place within the cell through arresting at the G2/M cell cycle stage, abnormal morphology of mitochondria, oxidative stress and other hallmarks of apoptosis at therapeutic doses [20-24]. Studies on apoptosis by the intracellular mechanism of polyene are still poorly understood, but reports of apoptosis continue to accumulate $[20-23,25,26]$.

\section{Azoles}

The azoles mainly consist of two subclasses based on the number of nitrogen atoms in the ring. One class comprises imidazoles having two nitrogen atoms in the azole ring and the other class comprises triazoles containing three nitrogen atoms in the cyclic ring [11, 27]. The first azoles, the

Table 1. Conventional antifungals reported to induce fungal apoptosis.

\begin{tabular}{|c|c|c|c|}
\hline Classification & Mechanisms of action & Compound & Reference \\
\hline \multirow[t]{2}{*}{ Polyene } & Artificial pore formation through interacting with ergosterol & Amphotericin B & {$[22,23]$} \\
\hline & & Nystatin & {$[80,81]$} \\
\hline \multirow[t]{3}{*}{ Azole } & Interferes with sterol 14- $\alpha$-demethylase, a cytochrome P450 dependent enzyme & Fluconazole & {$[34,36]$} \\
\hline & & Itraconzole & {$[33,82]$} \\
\hline & & Miconazole & {$[29,83]$} \\
\hline Echinocandins & & Caspofungin & {$[37,38,47]$} \\
\hline
\end{tabular}


imidazoles (clotrimazole and miconazole), were marketed in 1969 as topical alternatives to nystatin, one of the polyenes, and griseofulvin for cutaneous and mucocutaneous infection [28]. The first-generation triazole drugs were released in the 1990s [11]. In the last few decades, several azole drugs have been used against various fungal diseases. Blocking the biosynthetic pathway of ergosterol is a major mechanism of azole along with the accumulation of a toxic methylated sterol that stops cell growth $[15,29,30]$. This enzyme is encoded by the ERG11 gene. Its inactivation leads to the accumulation of methylated sterols such as the toxic 14- $\alpha$-methyl-ergosta-8-ene-3,6-diol in fungal cells by blocking ergosterol production [11, 13, 18]. The sterols inserted between the phospholipids moderate the fluidity, and the decrease in the ergosterol content interferes with the integrity and functionality of the cell membrane [31]. The integrity of the cell membrane is also impaired by the accumulation of sterol precursors and the reduction of ergosterol [7, 11]. Maintaining membrane integrity in membrane function is important for cell survival. Membranes protect cells from the external environment and regulate cellular responses [32]. The loss of membrane fluidity can disrupt with the interaction between the cell wall and the plasma membrane, affecting the biosynthesis of the cell wall, and thereby weakening it [18]. Fluconazole, one of the triazoles, induces alterations in cell wall proteomes, including abundant protein changes associated with cell wall integrity [18]. Changes in metabolite pools and oxidative damage and mitochondrial dysfunction have been reported [33-35]. These physiological disorders suggested that some azoles (fluconazole, itraconazole) trigger mitochondria-mediated apoptosis [33, 36].

\section{Echinocandins}

Echinocandin is the latest class of antimycotic substances and semi-synthetic lipopeptides consisting of N-linked cyclic hexapeptides in the fatty acid alkyl side chains [11, 29]. This class includes caspofungin, micafungin, and anidulafungin. These lipopeptides act on glucans, a major component of the fungal cell wall [11, 13, 29]. Composed mainly of glucan and chitin, the fungal cell wall is considered to be a unique feature that has a protective effect against environmental stress factors and host immunity [7]. Common molecules such as chitin, glucan, mannan and glycoproteins are contained in the cell walls of yeast and filamentous fungi. These components are critical to protecting cells from environmental stress and osmotic pressure, and they are crosslinked to preserve cell integrity and shape [18]. Echinocandins inactivate cell wall biosynthesis by inhibiting $\beta-1,3$-glucan synthase enzyme responsible for $\beta$-1,3-glucan biosynthesis. $\beta$-1,3-glucan is a fungal cell wall component and affects cell integrity due to a decrease in $\beta$-glucan levels $[7,18,37]$. The $1,3-\beta$-glucan synthase enzyme consists of three FKS subunits called FKS1, FKS2, and FKS3 [11, 13, 29]. Echinocandins act as non-competitive inhibitors of $\beta$-1,3-glucan synthase and are not cytotoxic to mammalian cells. Their action reduces the thickness of the cell wall and ultimately makes them osmotically sensitive $[24,27,38]$. The mode of action of echinocandins is known, but the physiological mechanism is unknown. As an indication of the intracellular response, caspofungin and micafungin have reported triggering caspase-dependent apoptosis [38, 39].

\section{The Resistance Machinery}

The emergence of resistance to multiple antimicrobial agents in pathogenic bacteria, fungi, viruses and parasites has become a serious threat [40]. The molecular mechanisms that cause antifungal resistance are complex. Fungal cells generally have to adapt to the presence of toxic drugs. Molecular survival strategies include mutations of drug targets that reduce the affinity for drugs, overexpression of targeted proteins by the expression of the efflux system, modification of the promoter region of the gene, drug degradation, and polymorphic drug responses [13]. In fungi, two drug release systems are regulated during drug removal in the cytoplasm, the ATP-coupled cassette (ABC) superfamily and the major facilitator superfamily (MFS) [41]. Activation of the membrane-associated efflux pump reduces the intracellular concentration by releasing the drug outside the cell, so the amount of drug at the site of action is small [6, 16, 41, 42].

The ERG11 gene encodes the enzyme lanosterol $14 \alpha-$ demethylase in yeast, the target enzyme of azoles. Thus, the point mutation of this gene reduces the affinity or inability to bind the drug enzyme by altering the azole binding site $[16,43,44]$. Besides the mutation of the gene encoding the lanosterol $14 \alpha$-demethylase enzyme, the mechanism of resistance changes other enzymes in the same biosynthetic pathway. The effect of azole reduces ergosterol in the cell membrane and accumulates $14 \alpha-$ methyl-3,6-diol, a toxic product [16, 44]. Mutations in the ERG3 gene prevent the formation of 14 $\alpha$-methyl-3,6-diol from $14 \alpha$-methylpelecosterol and accumulate precursors that can replace cytoplasmic ergosterol. Mutations in ergosterol biosynthesis genes such as ERG2, ERG6, and ERG24 are also associated with decreased susceptibility to 
azole. Changes in the ergosterol biosynthetic pathway and low ergosterol level can no longer effectively inhibit ergosterol synthesis by the usual therapeutic concentrations of azole [16].

The resistance to echinocandins is often acquired by modifying amino acid residues in the FKS1 and FKS2 subunits of $\beta$-1,3-glucan synthase, efflux pumps and degradation pathways [13]. The mutations in FKS1 and FKS2 that code for catalytic subunit genes can be amino acid substitutions accompanied by a dramatic reduction in glucan synthase activity [45-47]. The FKS1 and FKS2 amino acid residue substitutions can vary depending on fungal species, but also cause echinocandin resistance [13, 48]. Dimorphic fungi have a natural resistance to echinocandins during the pathogenic phase, but the resistance mechanisms of the $\beta$-glucan synthase inhibitors remain to be elucidated [44]. Also, their susceptibility was reduced in vivo owing to the elevation of chitin levels in the cell wall [49]. In turn, polyene resistance generally involves the depletion of ergosterol attributable to the loss of function of the ergosterol biosynthetic gene $[41,44,50]$.

\section{Exploration of Novel Antifungals and Targets}

The metabolic processes of ergosterol biosynthesis, membrane stability and maintenance and cell wall remodeling are long-established drug targets. Proposing to be promising alternative strategies, several efforts are underway to discover and develop new natural and synthetic antimicrobial agents.

\section{Programmed Cell Death (PCD) in Fungi}

The antifungal drugs mentioned above have one thing in common in that they trigger the apoptotic cell death pathway [22, 33, 36, 38, 39]. Awareness of the importance of PCD in fungi has led to a reassessment of the mode of action of working antifungal agents. This phenomenon suggested that induced PCD could be a common mode of action for many antifungal agents [51]. PCD is induced by various triggers and is accompanied by most of the typical characteristics of multicellular apoptotic cell death. Nonetheless, yeast systems have important differences compared to mammalian apoptosis. Most significantly, the entire extrinsic pathway is not found in fungi $[51,52]$.

The intrinsic pathway is characterized by an increase of permeability in mitochondrial outer membrane [52]. Organelle swelling and rupture of inner mitochondrial outer membranes are due to the opening of calcium and voltagedependent channels in the inner mitochondrial membrane
[52, 53]. Permeabilization of the outer mitochondrial membrane is followed by the release from mitochondrial proteins of cytochrome $c$, Smac/DIABLO, OMI/HtrA2, Apoptosis Inducing Factor (AIF) and endonuclease G [52, 54]. The released cytochrome $c$ binds to Apaf1, triggering oligomerization, followed by pro-caspase- 9 recruitment and autoactivation $[52,55]$. The release of cytochrome $c$ from yeast was first demonstrated to express the human pro-apoptotic protein Bax. The expression of Bax significantly decreased cytochrome $c$ oxidase and cytochrome $c$ release to cytosol $[52,56]$. Dysfunction of mitochondrial function such as AIF and cytochrome $c$ release, channel opening upon human Bax expression, mitochondrial fragmentation, and changes in mitochondrial membrane potential [57]. Release of cytochrome $c$ into the cytoplasm provokes the caspase-cascade as a representative of other apoptotic proteases. Cytochrome $c$ released from mitochondria binds to apoptotic protease-activating factors in the cytosol [55].

Caspases, cysteine-dependent aspartate-specific proteases, play an important role in the apoptotic signaling pathway and are generally activated in the early stages of apoptosis [10,52]. Saccharomyces cerevisiae, C. albicans, and Schizosaccharomyces pombe have a single metacaspase encoding gene Yca1p, one ortholog of mammalian caspases $[10,58]$. A. fumigatus, A. nidulans, Neurospora crassa, and Cryptococcus neoformans have genes encoding two metacaspases [10]. Although the proteolytic specificity of the metacaspases differs from that of caspase, it degrades similar death-related molecules in that it is hydrolyzed after a basic amino acid residue that is not an acidic residue $[10,54]$. Metacaspases are also followed by the loss of ubiquitination control, the incomplete initiation of DNA replication and alteration of mRNA stability [54].

DNA nicking, the accumulation of reactive oxygen species, and intracellular activation of fungal caspases accompany PCD. The accumulation of reactive oxygen species is observed in almost all fungicidal cell death scenarios and plays an important role as an early signaling pathway for apoptosis [59-61]. The rate of early apoptosis was corroborated by the externalization of phosphatidylserine, reactive oxygen species production and loss of mitochondrial membrane potential, and the rate of late apoptosis was supported by nuclear fission, DNA damage, cytochrome $c$ and ATP release and increased intracellular calcium ion levels $[52,62,63]$. Although the full extent of the role remains, many fungicidal drugs induce the apoptotic cellular death pathway that involves a genetic and metabolic cascade and then eventually damaged nucleic acid, proteins and lipid [15]. Amphotericin B, 
itraconazole, and caspofungin, which are the most commonly used antifungal agents, have recently been shown to process a yeast apoptosis [23, 36, 38]. More research is needed to show how metacaspase 1 or other proteases contribute to this process, but they proceed through the caspase-dependent pathway. Several caspaselike proteases such as Kex1 and Esp1 are involved in apoptotic cell death independent of caspase Yca1p [38]. Future studies are needed to determine whether the caspase-independent pathway is also involved in apoptosis control at the exposures of antifungal drugs.

\section{Use of Drug Combinations}

A promising therapeutic strategy to increase drug efficacy and overcome the emergence of resistant fungi is to use drug combinations [3, 64]. This pragmatic strategy emphasizes the disruption of biofilms and the reduction of drug resistance development and bypasses the pipeline, which is costly and time-consuming for new drug development [42, 65, 66]. Especially, biofilm-related infection requires clinical studies to support the benefits of combination therapy over antifungal monotherapy [65]. Despite the improved activity of antifungals, complete eradication of sessile organisms within mature biofilms has not been demonstrated $[67,68]$. Combinations of some antifungal drugs themselves or new potential antifungal agents against A. fumigatus biofilms in vitro have been shown to cause enhancement of antifungal activity, but the susceptibility was lower than that of planktonic cells [69]. Therefore, new therapeutic strategies against biofilm-associated mycoses are urgently needed $[65,69]$.

The most common reason to use or investigate combinations of antifungal agents is to achieve the potential for synergy effect. However, harmful effects including activity attenuation, increased tolerance or toxicity, and increased costs and drug interactions show the risk of combination therapy. Application should be carefully considered with the difficulty of interpreting much in vitro, animal and clinical data [70]. For instance, the combination of flucytosine and amphotericin B for the treatment of cryptococcal meningitis has a higher rate of recurrence and less frequent relapses than with amphotericin B monotherapy $[11,16]$. In addition, this combination therapy showed lower renal toxicity than monotherapy. However, amphotericin B-induced glomerular filtration reduced hepatic toxicity and reduced flucytosine elimination [16].

High cost and serious side effects limit the combination of antifungal agents. In addition, contradictory results of the synergistic or antagonistic action of various antifungal combinations have been reported. Therefore, the focus of the study has shifted toward examining the combination of typical antifungal agents and non-antifungal agents [3]. For instance, there is a combination of fluconazole with other classes of non-antifungal agents such as calcineurin inhibitors, heat shock protein 90 (Hsp90) inhibitors, calcium homeostasis modulators and traditional medical drugs. Interestingly, some of these combinations showed a synergistic effect on conventional drug-resistant strains. The main mechanism of this synergistic effect reveals to increase the permeability of the cell membrane, reduce the efflux of antifungal agents, interfere with intracellular ion homeostasis, inhibit the protein and enzyme activity required for fungal survival, and inhibit biofilm formation [3]. Hsp90 is known to regulate azole resistance through the major downstream effectors such as calcineurin, and Mkc1 kinase. Hsp90 stabilizes calcineurin by direct interaction. Inhibition of Hsp90 depletes or inactivates calcineurin. Interfering with the Hsp90 circuit lowers the susceptibility of the fungus to the antimicrobial agent. Using these characteristics, it was suggested to examine the combination in the direction of lowering the resistance of the fungus [7]. In other cases, several antimicrobial peptides (AMPs), HsAFP1, RsAFP2, and RsAFP1 synergize with antimicrobial agents such as caspofungin and/or amphotericin B for both plankton and biofilm cells, while a variety of linear HsAFP1- derived peptides show synergistic activity (Table 2)

Table 2. Antifungal peptides induce synergistic effect.

\begin{tabular}{llll}
\hline \multicolumn{1}{c}{ Peptides } & \multicolumn{1}{c}{ Origin } & \multicolumn{1}{c}{ Antifungals } & \multicolumn{1}{c}{ Species } \\
\hline Bovine Lactoferrin & Bos taurus & Clotrimazole, Fluconazole & Candida albicans, C. glabrata \\
HsAFP1 & Heuchera sanguinea & Caspofungin, Amphotericin B & C. albicans \\
RsAFP1 & Raphanus sativus & Caspofungin & C. albicans \\
RsAFP2 & R. sativus & Caspofungin, Amphotericin B & C. albicans \\
Bacillomycin D & Bacillus subtilis B38 & Amphotericin B & C. albicans \\
CaThi & Capsicum annuum & Fluconazole & C. albicans, C. tropicalis, C. parapsilosis,
\end{tabular}


Table 3. Antifungal peptides and their mechanism of action.

\begin{tabular}{|c|c|c|c|c|c|}
\hline Peptides & Sources & Sequences & Mechanisms & PDB ID & References \\
\hline Coprisin & $\begin{array}{l}\text { Dung beetle } \\
\text { (Copris Tripartitus) }\end{array}$ & $\begin{array}{l}\text { VTCDVLSFEAKGIAVNHSACALHC } \\
\text { IALRKKGGSCQNGVCVCRN-NH }{ }_{2}\end{array}$ & Apoptosis & 2LN4 & {$[91,92]$} \\
\hline Arenicin-1 & $\begin{array}{l}\text { lugworm } \\
\text { (Arenicolamarina) }\end{array}$ & $\begin{array}{l}\text { KWKLFKKIEKVGQNIRDGIIKAGP } \\
\text { AVAVVGQATQIAK-NH }{ }_{2}\end{array}$ & $\begin{array}{l}\text { Membrane disruption, } \\
\text { Apoptosis }\end{array}$ & 2JSB & [93-95] \\
\hline Cecropin A & $\begin{array}{l}\text { Silk Moth } \\
\text { (Hyalophora cecropia) }\end{array}$ & $\begin{array}{l}\text { KWKLFKKIEKVGQNIRDGIIKAGP } \\
\text { AVAVVGQATQIAK-NH } \\
2\end{array}$ & Apoptosis & ND & {$[92,96]$} \\
\hline LL-37 & $\begin{array}{l}\text { Human } \\
\text { (Homosapiens) }\end{array}$ & $\begin{array}{l}\text { LLGDFFRKSKEKIGKEFKRIVQRIKDF } \\
\text { LRNLVPRTES }\end{array}$ & $\begin{array}{l}\text { Inhibition of cell } \\
\text { wall remodeling process }\end{array}$ & $2 \mathrm{~K} 6 \mathrm{O}$ & {$[97,98]$} \\
\hline Melittin & $\begin{array}{l}\text { European honeybee } \\
\text { (Apismellifera) }\end{array}$ & $\begin{array}{l}\text { GIGAVLKVLTTGLPALISWIKRKRQQ- } \\
\mathrm{NH}_{2}\end{array}$ & $\begin{array}{l}\text { Membrane } \\
\text { permeabilization, } \\
\text { Apoptosis }\end{array}$ & $2 \mathrm{MLT}$ & [99] \\
\hline Papiliocin & $\begin{array}{l}\text { Swallowtail butterfly } \\
\text { (Papilioxuthus) }\end{array}$ & $\begin{array}{l}\text { KWKLFKKIEKVGQNIRDGIIKAGP } \\
\text { AVAVVGQATQIAK-NH }{ }_{2}\end{array}$ & $\begin{array}{l}\text { Membrane perturbation, } \\
\text { Apoptosis }\end{array}$ & 2LA2 & [100-102] \\
\hline Scolopendin 1 & $\begin{array}{l}\text { Centipede } \\
\text { (Scolopendrasubspinipesmutilans) }\end{array}$ & $\begin{array}{l}\text { MDSFQKIEKIGEGTYGVVYKAKDKVSG } \\
\text { RLVALKKIRLENESEGVPSTA-NH }{ }_{2}\end{array}$ & Apoptosis & ND & [103] \\
\hline Scolopendin 2 & $\begin{array}{l}\text { Centipede } \\
\text { (Scolopendrasubspinipesmutilans) }\end{array}$ & AGLQFPVGRIGRLLRK & $\begin{array}{l}\text { Membrane disruption, } \\
\text { Pore formation, } \\
\text { Apoptosis, }\end{array}$ & ND & {$[104,105]$} \\
\hline
\end{tabular}

ND: Not Determined.

[71]. Ultimately, although hard to perform, combination therapies should seek out efficient treatments and drive potent, evidence-based research for evaluation [69, 72].

\section{AMPs as Novel Antifungal Agents}

A new antifungal agent candidate preferably should have a broad spectrum of activity, selective mechanisms of action, reduction/decrease of host toxicity, slight antagonistic interactions with other drugs and improvement of pharmacodynamics and pharmacokinetics [16, 73]. One attractive class of antifungals is AMPs, which are an important part of the innate immune system of all living organisms for infection by pathogens [74, 75]. AMPs are regulated through a variety of innate immune systems rather than direct action on pathogens, and there is little increased resistance [76]. Natural AMPs generally exhibit a wide spectrum of activity against viruses, Gram-negative bacteria and Gram-positive bacteria, fungi, eukaryotic parasites and multidrug-resistant microorganisms. They do not easily induce resistance as compared with conventional antibiotics due to their ability to bypass the common resistance mechanisms [74, 76]. AMPs are composed of fewer than 100 amino acid residues commonly used for cell transfer and are rich in cationic and hydrophobic residues arranged in different groups depending on amino acid composition, size and morphology [74,77]. Although AMPs have been classified into several groups based on structures or sequences such as $\alpha$-helical, cysteine-rich, glycine-rich and proline-rich peptides, AMPs generally have certain properties such as cationic charge and amphipathicity [78].

Their function is primarily exerted through disruption of viral, bacterial or fungal membranes with electrostatic and/or hydrophobic interaction and allowing leakage of intracellular contents $[10,18]$. This physicochemical mechanism reduces the development of resistance because the target of AMPs is the cell membrane and redesign for damaged membranes is inefficient. AMPs also have multimodal mechanisms for attacking pathogens, increasing the probability of success [76]. AMPs appear to possess multiple mechanisms of action involving extracellular binding, nonlytic ATP release, potassium ion efflux, internalization, and interaction with the intracellular targets (Table 3) [79]. They trigger signal transduction pathways and a range of interaction with surface receptors, to interact with specific intracellular targets such as protein, DNA and RNA without significantly permeabilizing the cell membrane $[10,15,18]$.

Antifungal peptides can pass through the plasma membrane and intracellular targets such as the mitochondrial membrane, nucleotides (RNA and DNA), a specific enzyme, protein synthesis machinery or a cellular protein target, would be accessible and vulnerable to the antifungal protein action [30]. Various AMP-based drugs are currently being tested in clinical trials, which point to the potential 


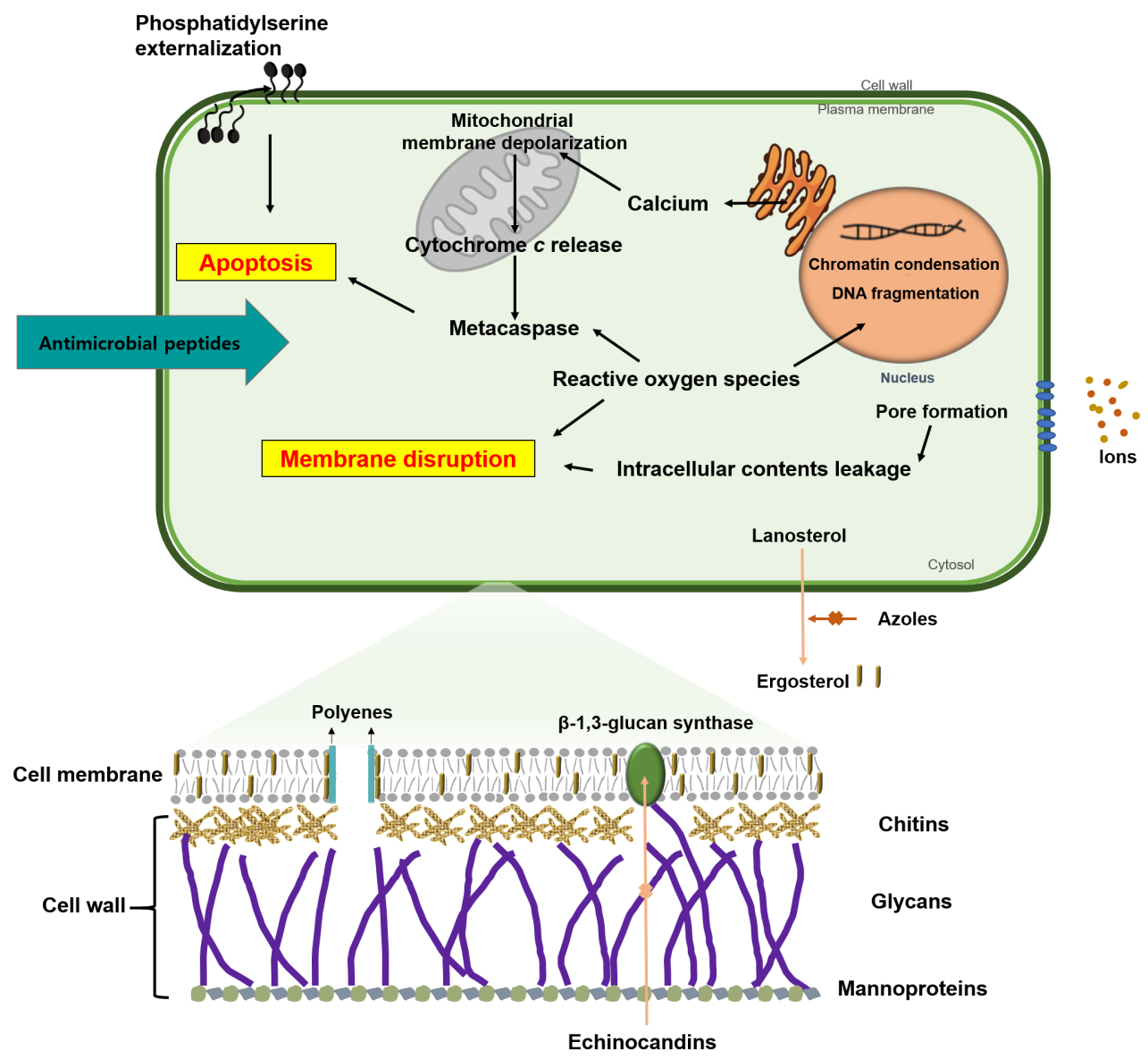

Fig. 1. Overview of mechanism of conventional antifungals and apoptosis.

use of AMP-based peptides to treat microbial infections [71]. The antifungal agent currently used in clinical therapeutics has also been isolated by the screening of natural products [1]. Thus, AMPs have potent potential as a suitable alternative to conventional antifungal agents.

Although the misuse and overuse of conventional antifungal drugs have major drawbacks attributable to toxic effect and evolution of antibiotic resistance, they have been used as clinical therapeutics. For improving antifungal efficacy, researchers and clinicians all over the world are trying to develop new antimicrobial agents and novel approaches. In this review, we suggested several strategies for overcoming this problem. Antifungal mechanisms of clinically used drugs target the cell wall and cell membrane which are the specific characteristics of fungi. In recent research, these drugs have been shown to share an intracellular process by which they trigger a hallmark of apoptosis with mitochondria- and caspase- dependence. Moreover, combination therapy has been proposed against various representative pathogenic fungi, and AMPs as potent and practical antimicrobial agents. Further investigations will be needed for clinical application, but these strategies could be used to lead the development of effective and short-term antifungal agents.

\section{Acknowledgments}

This work was supported by a grant from the NextGeneration BioGreen 21 Program (Project No. PJ01325603), Rural Development Administration, Republic of Korea.

\section{Conflict of Interest}

The authors have no financial conflicts of interest to declare.

\section{References}

1. Campoy S, Adrio JL. 2017. Antifungals. Biochem. Pharmacol. 133: $86-96$. 
2. Perfect JR. 2017. The antifungal pipeline: a reality check. Nat. Rev. Drug Discov. 16: 603-616.

3. Liu S, Hou Y, Chen X, Gao Y, Li H, Sun S. 2014. Combination of fluconazole with non-antifungal agents: a promising approach to cope with resistant Candida albicans infections and insight into new antifungal agent discovery. Int. J. Antimicrob. Agents. 43: 395-402.

4. Brown GD, Denning DW, Gow NA, Levitz SM, Netea MG, White TC. 2012. Hidden killers: human fungal infections. Sci. Transl. Med. 4: 165rv113.

5. Shor E, Chauhan N. 2015. A case for two-component signaling systems as antifungal drug targets. PLoS Pathog. 11: e1004632.

6. Pierce CG, Srinivasan A, Ramasubramanian AK, LopezRibot JL. 2015. From biology to drug development: new approaches to combat the threat of fungal biofilms. Microbiol. Spectr. 3(3).

7. Juvvadi PR, Lee SC, Heitman J, Steinbach WJ. 2017. Calcineurin in fungal virulence and drug resistance: Prospects for harnessing targeted inhibition of calcineurin for an antifungal therapeutic approach. Virulence 8: 186-197.

8. Bassetti M, Garnacho-Montero J, Calandra T, Kullberg B, Dimopoulos G, Azoulay E, et al. 2017. Intensive care medicine research agenda on invasive fungal infection in critically ill patients. Intensive Care Med. 43: 1225-1238.

9. Fernandez J, Acevedo J, Wiest R, Gustot T, Amoros A, Deulofeu $C$, et al. 2017. Bacterial and fungal infections in acute-on-chronic liver failure: prevalence, characteristics and impact on prognosis. Gut. 67(10): 1870-1880.

10. Biswas C, Zuo X, Chen SC, Schibeci SD, Forwood JK, Jolliffe KA, et al. 2014. Functional disruption of yeast metacaspase, Mca1, leads to miltefosine resistance and inability to mediate miltefosine-induced apoptotic effects. Fungal Genet. Biol. 67: 71-81.

11. Nett JE, Andes DR. 2016. Antifungal agents: spectrum of activity, pharmacology, and clinical indications. Infect. Dis. Clin. North Am. 30: 51-83.

12. Shah AH, Singh A, Dhamgaye $S$, Chauhan N, Vandeputte $P$, Suneetha KJ, et al. 2014. Novel role of a family of major facilitator transporters in biofilm development and virulence of Candida albicans. Biochem. J. 460: 223-235.

13. Parente-Rocha JA, Bailao AM, Amaral AC, Taborda CP, Paccez JD, Borges CL, et al. 2017. Antifungal resistance, metabolic routes as drug targets, and new antifungal agents: an overview about endemic dimorphic fungi. Mediators Inflamm. 2017: 9870679.

14. Fujita K, Tatsumi M, Ogita A, Kubo I, Tanaka T. 2014. Anethole induces apoptotic cell death accompanied by reactive oxygen species production and DNA fragmentation in Aspergillus fumigatus and Saccharomyces cerevisiae. FEBS J. 281: 1304-1313.

15. Belenky P, Camacho D, Collins JJ. 2013. Fungicidal drugs induce a common oxidative-damage cellular death pathway.
Cell Rep. 3: 350-358.

16. Fuentefria AM, Pippi B, Dalla Lana DF, Donato KK, de Andrade SF. 2018. Antifungals discovery: an insight into new strategies to combat antifungal resistance. Lett. Appl. Microbiol. 66: 2-13.

17. Teixeira-Santos R, Ricardo E, Guerreiro SG, Costa-deOliveira S, Rodrigues AG, Pina-Vaz C. 2015. New insights regarding yeast survival following exposure to liposomal amphotericin B. Antimicrob. Agents Chemother. 59: 6181-6187.

18. Hayes BM, Anderson MA, Traven A, van der Weerden NL, Bleackley MR. 2014. Activation of stress signalling pathways enhances tolerance of fungi to chemical fungicides and antifungal proteins. Cell Mol. Life Sci. 71: 2651-2666.

19. Grudzinski W, Sagan J, Welc R, Luchowski R, Gruszecki WI. 2016. Molecular organization, localization and orientation of antifungal antibiotic amphotericin B in a single lipid bilayer. Sci. Rep. 6: 32780.

20. Chudzik B, Koselski M, Czurylo A, Trebacz K, Gagos M. 2015. A new look at the antibiotic amphotericin B effect on Candida albicans plasma membrane permeability and cell viability functions. Eur. Biophys. J. 44: 77-90.

21. Almeida B, Silva A, Mesquita A, Sampaio-Marques B, Rodrigues F, Ludovico P. 2008. Drug-induced apoptosis in yeast. Biochim. Biophys. Acta 1783: 1436-1448.

22. Al-Dhaheri RS, Douglas LJ. 2010. Apoptosis in Candida biofilms exposed to amphotericin B. J. Med. Microbiol. 59: 149-157.

23. Phillips AJ, Sudbery I, Ramsdale M. 2003. Apoptosis induced by environmental stresses and amphotericin B in Candida albicans. Proc. Natl. Acad. Sci. USA 100: 14327-14332.

24. Guirao-Abad JP, Sanchez-Fresneda R, Alburquerque B, Hernandez JA, Arguelles JC. 2017. ROS formation is a differential contributory factor to the fungicidal action of Amphotericin B and Micafungin in Candida albicans. Int. J. Med. Microbiol. 307: 241-248.

25. Folk A, Balta C, Herman H, Ivan A, Boldura OM, Paiusan L, et al. 2017. Flucytosine and amphotericin B coadministration induces dose-related renal injury. Dose Response 15: 1559325817703461.

26. Mousavi SA, Robson GD. 2004. Oxidative and amphotericin B-mediated cell death in the opportunistic pathogen Aspergillus fumigatus is associated with an apoptotic-like phenotype. Microbiology 150: 1937-1945.

27. Prasad R, Shah AH, Rawal MK. 2016. Antifungals: mechanism of action and drug resistance. Adv. Exp. Med. Biol. 892: 327-349.

28. Allen D, Wilson D, Drew R, Perfect J. 2015. Azole antifungals: 35 years of invasive fungal infection management. Exp. Rev. Anti Infect. Ther. 13: 787-798.

29. Delattin N, Cammue BP, Thevissen K. 2014. Reactive oxygen species-inducing antifungal agents and their activity against fungal biofilms. Future Med. Chem. 6: 77-90.

30. Rautenbach M, Troskie AM, Vosloo JA. 2016. Antifungal 
peptides: To be or not to be membrane active. Biochimie 130: $132-145$

31. de Oliveira Pereira F, Mendes JM, de Oliveira Lima E. 2013. Investigation on mechanism of antifungal activity of eugenol against Trichophyton rubrum. Med. Mycol. 51: 507513.

32. Portet T, Camps i Febrer F, Escoffre JM, Favard C, Rols MP, Dean DS. 2009. Visualization of membrane loss during the shrinkage of giant vesicles under electropulsation. Biophys. J. 96: 4109-4121.

33. Lee W, Lee DG. 2018. Reactive oxygen species modulate itraconazole-induced apoptosis via mitochondrial disruption in Candida albicans. Free Radic. Res. 52: 39-50.

34. Katragkou A, Alexander EL, Eoh H, Raheem SK, Roilides E, Walsh TJ. 2016. Effects of fluconazole on the metabolomic profile of Candida albicans. J. Antimicrob. Chemother. 71: 635640 .

35. Mahl CD, Behling CS, Hackenhaar FS, de Carvalho e Silva MN, Putti J, Salomon TB, et al. 2015. Induction of ROS generation by fluconazole in Candida glabrata: activation of antioxidant enzymes and oxidative DNA damage. Diagn. Microbiol. Infect. Dis. 82: 203-208.

36. Lee W, Lee DG. 2018. A novel mechanism of fluconazole: fungicidal activity through dose-dependent apoptotic responses in Candida albicans. Microbiology 164: 194-204.

37. Feldmesser M, Kress Y, Mednick A, Casadevall A. 2000. The effect of the echinocandin analogue caspofungin on cell wall glucan synthesis by Cryptococcus neoformans. J. Infect. Dis. 182: 1791-1795.

38. Hao B, Cheng S, Clancy CJ, Nguyen MH. 2013. Caspofungin kills Candida albicans by causing both cellular apoptosis and necrosis. Antimicrob. Agents Chemother. 57: 326-332.

39. Shirazi F, Kontoyiannis DP. 2015. Micafungin triggers caspase-dependent apoptosis in Candida albicans and Candida parapsilosis biofilms, including caspofungin nonsusceptible isolates. Virulence 6: 385-394.

40. Lakshmaiah Narayana J, Chen JY. 2015. Antimicrobial peptides: possible anti-infective agents. Peptides 72: 88-94.

41. Cowen LE, Sanglard D, Howard SJ, Rogers PD, Perlin DS. 2014. Mechanisms of antifungal drug resistance. Cold Spring Harb Perspect Med. 5: a019752.

42. Cui J, Ren B, Tong Y, Dai H, Zhang L. 2015. Synergistic combinations of antifungals and anti-virulence agents to fight against Candida albicans. Virulence 6: 362-371.

43. Hagiwara D, Watanabe A, Kamei K, Goldman GH. 2016. Epidemiological and genomic landscape of azole resistance mechanisms in Aspergillus fungi. Front Microbiol. 7: 1382.

44. Kanafani ZA, Perfect JR. 2008. Antimicrobial resistance: resistance to antifungal agents: mechanisms and clinical impact. Clin. Infect. Dis. 46: 120-128.

45. Shields RK, Nguyen MH, Press EG, Cumbie R, Driscoll E, Pasculle AW, et al. 2015. Rate of FKS mutations among consecutive Candida isolates causing bloodstream infection.
Antimicrob. Agents Chemother. 59: 7465-7470.

46. Pham CD, Iqbal N, Bolden CB, Kuykendall RJ, Harrison LH, Farley MM, et al. 2014. Role of FKS mutations in Candida glabrata: MIC values, echinocandin resistance, and multidrug resistance. Antimicrob. Agents Chemother. 58: 4690-4696.

47. Fekkar A, Meyer I, Brossas JY, Dannaoui E, Palous M, Uzunov $\mathrm{M}$, et al. 2013. Rapid emergence of echinocandin resistance during Candida kefyr fungemia treatment with caspofungin. Antimicrob. Agents Chemother. 57: 2380-2382.

48. Jensen RH, Johansen HK, Arendrup MC. 2013. Stepwise development of a homozygous S80P substitution in Fks1p, conferring echinocandin resistance in Candida tropicalis. Antimicrob. Agents Chemother. 57: 614-617.

49. Lee KK, Maccallum DM, Jacobsen MD, Walker LA, Odds FC, Gow NA, et al. 2012. Elevated cell wall chitin in Candida albicans confers echinocandin resistance in vivo. Antimicrob. Agents Chemother. 56: 208-217.

50. Vincent BM, Lancaster AK, Scherz-Shouval R, Whitesell L, Lindquist S. 2013. Fitness trade-offs restrict the evolution of resistance to amphotericin B. PLoS Biol. 11: e1001692.

51. Shlezinger N, Goldfinger N, Sharon A. 2012. Apoptotic-like programed cell death in fungi: the benefits in filamentous species. Front. Oncol. 2: 97.

52. Madeo F, Herker E, Wissing S, Jungwirth H, Eisenberg T, Frohlich KU. 2004. Apoptosis in yeast. Curr. Opin. Microbiol. 7: 655-660.

53. Murgia M, Rizzuto R. 2015. Molecular diversity and pleiotropic role of the mitochondrial calcium uniporter. Cell Calcium 58: 11-17.

54. Carmona-Gutierrez D, Eisenberg T, Buttner S, Meisinger C, Kroemer G, Madeo F. 2010. Apoptosis in yeast: triggers, pathways, subroutines. Cell Death Differ. 17: 763-773.

55. Pereira C, Camougrand N, Manon S, Sousa MJ, Corte-Real M. 2007. ADP/ATP carrier is required for mitochondrial outer membrane permeabilization and cytochrome $c$ release in yeast apoptosis. Mol. Microbiol. 66: 571-582.

56. Shirazi F, Kontoyiannis DP. 2013. The calcineurin pathway inhibitor tacrolimus enhances the in vitro activity of azoles against Mucorales via apoptosis. Eukaryot Cell. 12: 12251234.

57. Eisenberg T, Buttner S, Kroemer G, Madeo F. 2007. The mitochondrial pathway in yeast apoptosis. Apoptosis 12: 1011-1023.

58. Mazzoni C, Falcone C. 2008. Caspase-dependent apoptosis in yeast. Biochim. Biophys. Acta 1783: 1320-1327.

59. Costa V, Moradas-Ferreira P. 2001. Oxidative stress and signal transduction in Saccharomyces cerevisiae: insights into ageing, apoptosis and diseases. Mol. Aspects Med. 22: 217-246.

60. Ludovico P, Madeo F, Silva M. 2005. Yeast programmed cell death: an intricate puzzle. IUBMB Life 57: 129-135.

61. Perrone GG, Tan SX, Dawes IW. 2008. Reactive oxygen species and yeast apoptosis. Biochim. Biophys. Acta 1783: 1354-1368. 
62. Leger T, Garcia C, Ounissi M, Lelandais G, Camadro JM. 2015. The metacaspase (Mca1p) has a dual role in farnesolinduced apoptosis in Candida albicans. Mol. Cell Proteomics 14: 93-108.

63. Kyrylkova K, Kyryachenko S, Leid M, Kioussi C. 2012. Detection of apoptosis by TUNEL assay. Methods Mol. Biol. 887: 41-47.

64. Spitzer M, Robbins N, Wright GD. 2017. Combinatorial strategies for combating invasive fungal infections. Virulence 8: 169-185.

65. Tobudic S, Kratzer C, Lassnigg A, Graninger W, Presterl E. 2010. In vitro activity of antifungal combinations against Candida albicans biofilms. J. Antimicrob. Chemother. 65: 271274.

66. Liao Y, Yang S, Cong L, Lu X, Ao J, Yang R. 2014. In vitro activities of antifungal combinations against biofilms and planktonic forms of clinical Trichosporon asahii isolates. Antimicrob. Agents Chemother. 58: 7615-7616.

67. Shuford JA, Piper KE, Steckelberg JM, Patel R. 2007. In vitro biofilm characterization and activity of antifungal agents alone and in combination against sessile and planktonic clinical Candida albicans isolates. Diagn. Microbiol. Infect. Dis. 57: 277-281.

68. Bachmann SP, Ramage G, VandeWalle K, Patterson TF, Wickes BL, Lopez-Ribot JL. 2003. Antifungal combinations against Candida albicans biofilms in vitro. Antimicrob. Agents Chemother. 47: 3657-3659.

69. Zeng R, Li M, Chen Q, Wang L, Zhan P, Wang C, et al. 2014. In vitro analyses of mild heat stress in combination with antifungal agents against Aspergillus fumigatus biofilm. Antimicrob. Agents Chemother. 58: 1443-1450.

70. Garbati MA, Alasmari FA, Al-Tannir MA, Tleyjeh IM. 2012. The role of combination antifungal therapy in the treatment of invasive aspergillosis: a systematic review. Int. J. Infect. Dis. 16: e76-81.

71. Cools TL, Struyfs C, Cammue BP, Thevissen K. 2017. Antifungal plant defensins: increased insight in their mode of action as a basis for their use to combat fungal infections. Future Microbiol. 12: 441-454.

72. Spanakis EK, Aperis G, Mylonakis E. 2006. New agents for the treatment of fungal infections: clinical efficacy and gaps in coverage. Clin. Infect. Dis. 43: 1060-1068.

73. van der Weerden NL, Bleackley MR, Anderson MA. 2013. Properties and mechanisms of action of naturally occurring antifungal peptides. Cell Mol. Life Sci. 70: 3545-3570.

74. Mardirossian M, Grzela R, Giglione C, Meinnel T, Gennaro R, Mergaert $\mathrm{P}$, et al. 2014. The host antimicrobial peptide Bac71-35 binds to bacterial ribosomal proteins and inhibits protein synthesis. Chem. Biol. 21: 1639-1647.

75. Libardo MDJ, Wang TY, Pellois JP, Angeles-Boza AM. 2017. How does membrane oxidation affect cell delivery and cell killing? Trends Biotechnol. 35: 686-690.

76. Wang S, Zeng X, Yang Q, Qiao S. 2016. Antimicrobial peptides as potential alternatives to antibiotics in food animal industry. Int. J. Mol. Sci. 17.

77. Shivange G, Monisha M, Nigam R, Kodipelli N, Anindya R. 2016. RecA stimulates AlkB-mediated direct repair of DNA adducts. Nucleic Acids Res. 44: 8754-8763.

78. Roy RN, Lomakin IB, Gagnon MG, Steitz TA. 2015. The mechanism of inhibition of protein synthesis by the prolinerich peptide oncocin. Nat. Struct. Mol. Biol. 22: 466-469.

79. Baev D, Li XS, Dong J, Keng P, Edgerton M. 2002. Human salivary histatin 5 causes disordered volume regulation and cell cycle arrest in Candida albicans. Infect. Immun. 70: 4777-4784.

80. Serhan G, Stack CM, Perrone GG, Morton CO. 2014. The polyene antifungals, amphotericin B and nystatin, cause cell death in Saccharomyces cerevisiae by a distinct mechanism to amphibian-derived antimicrobial peptides. Ann. Clin. Microbiol. Antimicrob. 13: 18.

81. Semis R, Kagan S, Berdicevsky I, Polacheck I, Segal E. 2013. Mechanism of activity and toxicity of NystatinIntralipid. Med. Mycol. 51: 422-431.

82. Bendaha H, Yu L, Touzani R, Souane R, Giaever G, Nislow C, et al. 2011. New azole antifungal agents with novel modes of action: synthesis and biological studies of new tridentate ligands based on pyrazole and triazole. Eur. J. Med. Chem. 46: 4117-4124.

83. Vandenbosch D, Braeckmans K, Nelis HJ, Coenye T. 2010. Fungicidal activity of miconazole against Candida spp. biofilms. J. Antimicrob. Chemother. 65: 694-700.

84. Kuipers ME, de Vries HG, Eikelboom MC, Meijer DK, Swart PJ. 1999. Synergistic fungistatic effects of lactoferrin in combination with antifungal drugs against clinical Candida isolates. Antimicrob. Agents Chemother. 43: 2635-2641.

85. Wakabayashi H, Abe S, Okutomi T, Tansho S, Kawase K, Yamaguchi H. 1996. Cooperative anti-Candida effects of lactoferrin or its peptides in combination with azole antifungal agents. Microbiol. Immunol. 40: 821-825.

86. Vriens K, Cools TL, Harvey PJ, Craik DJ, Spincemaille P, Cassiman D, et al. 2015. Synergistic activity of the plant defensin hsafp1 and caspofungin against Candida albicans biofilms and planktonic cultures. PLoS One 10: e0132701.

87. Vriens K, Cools TL, Harvey PJ, Craik DJ, Braem A, Vleugels J, et al. 2016. The radish defensins RsAFP1 and RsAFP2 act synergistically with caspofungin against Candida albicans biofilms. Peptides 75: 71-79.

88. Aerts AM, Carmona-Gutierrez D, Lefevre S, Govaert G, Francois IE, Madeo F, et al. 2009. The antifungal plant defensin RsAFP2 from radish induces apoptosis in a metacaspase independent way in Candida albicans. FEBS Lett. 583: 2513-2516.

89. Tabbene O, Azaiez S, Di Grazia A, Karkouch I, Ben Slimene I, Elkahoui S, et al. 2016. Bacillomycin D and its combination with amphotericin B: promising antifungal compounds with powerful antibiofilm activity and wound- 
healing potency. J. Appl. Microbiol. 120: 289-300.

90. Taveira GB, Carvalho AO, Rodrigues R, Trindade FG, Da Cunha M, Gomes VM. 2016. Thionin-like peptide from Capsicum annuum fruits: mechanism of action and synergism with fluconazole against Candida species. BMC Microbiol. 16: 12 .

91. Lee J, Lee D, Choi H, Kim HH, Kim H, Hwang JS, et al. 2014. Structure-activity relationships of the intramolecular disulfide bonds in coprisin, a defensin from the dung beetle. BMB Rep. 47: 625-630.

92. Lee J, Hwang JS, Hwang IS, Cho J, Lee E, Kim Y, et al. 2012. Coprisin-induced antifungal effects in Candida albicans correlate with apoptotic mechanisms. Free Radic. Biol. Med. 52: 2302-2311.

93. Andra J, Jakovkin I, Grotzinger J, Hecht O, Krasnosdembskaya AD, Goldmann T, et al. 2008. Structure and mode of action of the antimicrobial peptide arenicin. Biochem. J. 410: 113-122.

94. Cho J, Lee DG. 2011. The antimicrobial peptide arenicin-1 promotes generation of reactive oxygen species and induction of apoptosis. Biochim. Biophys. Acta 1810: 1246-1251.

95. Park C, Lee DG. 2009. Fungicidal effect of antimicrobial peptide arenicin-1. Biochim. Biophys. Acta 1788: 1790-1796.

96. Yun J, Lee DG. 2016. Cecropin A-induced apoptosis is regulated by ion balance and glutathione antioxidant system in Candida albicans. IUBMB Life 68: 652-662.

97. Wang G. 2008. Structures of human host defense cathelicidin LL-37 and its smallest antimicrobial peptide KR-12 in lipid micelles. J. Biol. Chem. 283: 32637-32643.
98. Tsai PW, Cheng YL, Hsieh WP, Lan CY. 2014. Responses of Candida albicans to the human antimicrobial peptide LL-37. J. Microbiol. 52: 581-589.

99. Lee J, Lee DG. 2014. Melittin triggers apoptosis in Candida albicans through the reactive oxygen species-mediated mitochondria/caspase-dependent pathway. FEMS Microbiol. Lett. 355: 36-42.

100. Hwang B, Hwang JS, Lee J, Kim JK, Kim SR, Kim Y, et al. 2011. Induction of yeast apoptosis by an antimicrobial peptide, Papiliocin. Biochem. Biophys. Res. Commun. 408: 89-93.

101. Kim JK, Lee E, Shin S, Jeong KW, Lee JY, Bae SY, et al. 2011. Structure and function of papiliocin with antimicrobial and anti-inflammatory activities isolated from the swallowtail butterfly, Papilio xuthus. J. Biol. Chem. 286: 41296-41311.

102. Lee J, Hwang JS, Hwang B, Kim JK, Kim SR, Kim Y, et al. 2010. Influence of the papiliocin peptide derived from Papilio xuthus on the perturbation of fungal cell membranes. FEMS Microbiol. Lett. 311: 70-75.

103. Choi H, Hwang JS, Lee DG. 2014. Identification of a novel antimicrobial peptide, scolopendin 1, derived from centipede Scolopendra subspinipes mutilans and its antifungal mechanism. Insect. Mol. Biol. 23: 788-799.

104. Lee H, Hwang JS, Lee J, Kim JI, Lee DG. 2015. Scolopendin 2, a cationic antimicrobial peptide from centipede, and its membrane-active mechanism. Biochim. Biophys. Acta 1848: 634-642.

105. Lee H, Hwang JS, Lee DG. 2016. Scolopendin 2 leads to cellular stress response in Candida albicans. Apoptosis 21: 856-865. 